\title{
O ESTADO SOCIOAMBIENTAL DE DIREITO E A GARANTIA DO MÍNIMO EXISTENCIAL ECOLÓGICO PARA INDIVÍDUOS HUMANOS E NÃO HUMANOS
}

\section{Giselle Maria Custódio Cardoso ${ }^{1}$}

RESUMO: Este artigo objetiva tratar o Estado Constitucional Ecológico (Socioambiental de Direito) como expressão última do constitucionalismo brasileiro e o Mínimo Existencial Ecológico como decorrência lógica daquele. O método de abordagem é indutivo, de procedimento é funcionalista e o de interpretação é histórico. A pesquisa é teórico-qualitativa, de objeto bibliográfico e objetivo descritivo. Enquanto resultado, apontou-se que o meio ambiente é partícula essencial à efetivação do mínimo vital e que a norma constitucional brasileira é socioambiental e biocêntrica, portanto, cabível ampliar o espectro da sua proteção as presentes e futuras gerações de humanos e não humanos.

PALAVRAS-CHAVE: Direitos fundamentais; garantias constitucionais; mínimo existencial ecológico; direito ambiental; animais não humanos.

\section{THE SOCIO-ENVIRONMENTAL STATE OF LAW AND THE GUARANTEE OF THE ECOLOGICAL EXISTENTIAL MINIMUM FOR HUMAN AND NON- HUMAN INDIVIDUALS}

\begin{abstract}
This article aims at discussing the Ecological Constitutional State (Socioenvironmental Law) as the ultimate expression of Brazilian constitutionalism and the Ecological Existential Minimum as its logical consequence. The method of approach is inductive, the procedure is functionalist and the interpretation is historical. The research is theoretical-qualitative with a bibliographic object and descriptive objective. As a result, assuming that the environment is essential to the effectiveness of the minimum vital and that the Brazilian constitutional norm is socio-environmental and biocentric, it is appropriate to extend the spectrum of its protection to the present and future generations of humans and nonhumans.
\end{abstract}

KEYWORDS: Fundamental rights; constitutional guarantees; ecological existential minimum; environmental law; nonhuman animals.

\section{INTRODUÇÃO}

$\mathrm{Na}$ última quadra histórica, os direitos fundamentais passaram a assumir posição de centralidade no sistema jurídico, instituindo uma ordem objetiva de valores que irradia sua

\footnotetext{
${ }^{1}$ Mestranda em Direito da Cidade pela Universidade do Estado do Rio de Janeiro - UERJ. Especialista em Direito Ambiental pela Escola de Magistratura do Estado do Rio de Janeiro - EMERJ. Graduada em Direito pela Universidade Federal do Rio de Janeiro - UFRJ. Assessora Jurídica da Procuradoria do Instituto Estadual do Ambiente - INEA. Lattes: http://lattes.cnpq.br/8022498643847126. E-mail: gisellecardoso@live.com
} 
força normativa por todo o ordenamento, condicionando a interpretação das normas e institutos jurídicos e vinculando a atuação dos poderes públicos.

Logo, para concretização desses direitos fundamentais — de ordem civil, política, econômica, social, culturais e ambiental — passou-se a traduzir, também, como essencialmente fundamental a existência de um Estado Democrático de Direito enquanto garantidor de níveis mínimos desses direitos, tendo a dignidade da pessoa humana como core de sua atuação.

A partir deste aspecto introduz-se o conceito de mínimo existencial, que em sua origem se liga ao reconhecimento dado pelo Tribunal Administrativo Federal alemão de um Existenzminimum como um direito subjetivo construído a partir do princípio da dignidade da pessoa humana, da cláusula do Estado Social e dos direitos à liberdade e à vida ${ }^{2}$.

Portanto, seria mediante a garantia do mínimo existencial do complexo de direitos humanos fundamentais que seria assegurado ao indivíduo, minimamente, a sua inserção na vida social, política e cultural, i.e., sendo possível superar a desigualdade mediante o acesso aos bens necessários à realização do ser.

O mínimo existencial assume, por conseguinte, uma dimensão que ultrapassa a noção do Estado Liberal para a realização das liberdades públicas e do Estado Social com a busca pela justiça social e concretização dos direitos sociais, qual seja, o Estado Socioambiental de Direito, no qual se busca a efetivação dos direitos difusos, dentre os quais está o meio ambiente, e se torna o mínimo existencial ecológico.

O mínimo existencial ecológico, como pressuposto do mínimo vital, trabalha o ambiente como um espaço ocupado pela vida humana e não humana e a norma constitucional como escopo protetivo de ambos.

Nesse aspecto, trabalha-se o Estado Constitucional Ecológico a partir de Canotilho, como um conceito amplo que pressupõe uma concepção integrada ou integrativa do ambiente e, consequentemente, um direito integrado e integrativo do ambiente, em que haja a proteção

\footnotetext{
2 Tribunal Constitucional Federal da Alemanha. BVerfGE 40, 121 (1975). "A comunidade estatal deve assegurar-lhes pelo menos as condições mínimas para uma existência digna e envidar os esforços necessários para integrar estas pessoas na comunidade, fomentando o seu acompanhamento e apoio na família ou por terceiros, bem como criando as indispensáveis instituições assistenciais" SARLET, Ingo Wolfgang. Direitos fundamentais sociais, mínimo existencial e direito privado: breves notas sobre alguns aspectos da possível eficácia dos direitos sociais nas relações entre particulares. In: SARMENTO, Daniel; GALDINO, Flávio (orgs.). Direitos fundamentais: estudos em homenagem ao Professor Ricardo Lobo Torres. Rio de Janeiro: Renovar, 2006, p. 565
} 
desse em sua integralidade, por todos os aspectos (natural, físico, químico, biológico) e indivíduos (humano e não humano) que o compõem (CANOTILHO, 2001, p. 12).

Mudança de paradigma que reconhece o direito ao ambiente como direito fundamental da pessoa humana - "reconhecendo o caráter vital da qualidade ambiental para o desenvolvimento humano em níveis compatíveis com a dignidade que lhe é inerente" (FENSTERSEIFER, 2014, pp. 74 - 96) - e que, se alinha ao biocentrismo constitucional, para também reconhecer essa garantia aos indivíduos vivos (animais) não humanos.

A partir da análise de tais elementos, o presente artigo objetiva tratar o Estado Constitucional Ecológico (Socioambiental de Direito) como expressão última do constitucionalismo brasileiro e o Mínimo Existencial Ecológico como decorrência lógica daquele.

Para tanto, faz-se uma introdução dos conceitos básicos inerentes aos direitos e garantias fundamentais, de modo a fundamentar que, a partir de 1988, o contorno constitucional de proteção ao meio ambiente e a todos os indivíduos vivos que nele habitam é expressado no Estado Constitucional Ecológico, cujo caráter biocêntrico permite que as garantias dele decorrentes sejam estendidas a todos os indivíduos vivos (humanos e não humanos).

O método de abordagem é indutivo, de procedimento é funcionalista e o de interpretação é histórico. A pesquisa é teórico-qualitativa, de objeto bibliográfico e objetivo descritivo.

\section{DIREITOS FUNDAMENTAIS E PLURALISMO CONSTITUCIONAL}

A partir de 1988, com o advento da Constituição, inaugurou-se novo reconhecimento à sua força normativa ${ }^{3}$. Substitui-se a concepção da lei fundamental como carta política por seu atual status de norma jurídica que, dotada de observação obrigatória, impõe, no exercício

\footnotetext{
${ }^{3}$ Uma das obras percussoras sobre o tema é: A força normativa da Constituição, de Konrad Hesse, extraída a partir de sua aula inaugural na cátedra da Universidade de Freiburg. Segundo o autor, a norma constitucional não tem existência autônoma em face da realidade, mas tão pouco se limita ao reflexo das condições fáticas. Sua essência reside na pretensão de eficácia, ou seja, de sua concretização na realidade imprimindo-lhe ordem e conformação. (HESSE, 1991. pp. 14-15).
} 
do poder pelo Estado, limites e deveres de atuação, em especial, na tutela dos direitos fundamentais. $^{4}$

Com o processo de incorporação de amplo elenco de direitos fundamentais aos textos constitucionais, bem como a expansão da jurisdição constitucional, mediante a ampliação do elenco de legitimados para a propositura das ações e a criação de novos instrumentos de controle concentrado, garantiu-se a proteção dos direitos fundamentais a partir do processo político majoritário ${ }^{5}$.

A constituição cidadã ampliou o rol de direitos fundamentais, atribuindo-os significado ímpar, uma vez que os reconheceu como elementos integrantes de identidade e continuidade da lei fundamental, razão pelo qual, vedou qualquer reforma constitucional tendente a suprimi-los ${ }^{6}$.

Interrompeu-se, portanto, o ciclo inicial de baixa normatividade das disposições que veiculavam os direitos fundamentais, em especial, das normas que declaravam os direitos sociais, antes remetidas à esfera programática de meras linhas diretoras aos poderes públicos e tidas como dotadas de eficácia limitada. ${ }^{7}$

Ainda, foi reconhecida uma dimensão subjetiva dos direitos fundamentais - de proteção de situações individuais em face do poder público e dos particulares - e uma objetiva - de consagração de uma ordem objetiva de valores essenciais a sociedade ${ }^{8}$, que projetam a unidade da Constituição e a congruência dos seus preceitos ${ }^{9}$.

\footnotetext{
${ }^{4}$ Sobre as transformações do direito constitucional contemporâneo, consulte-se por todos: BARROSO In: SOUZA NETO; SARMENTO, 2007. p. 203-250. Para uma análise crítica vide: SARMENTO In: 2009. p. 113-146. (org.),

${ }^{5}$ Insere-se, portanto, o exercício da jurisdição constitucional orgânica e das liberdades no complexo de mecanismos de natureza normativa, institucional ou processual tendentes a assegurar a plena realização dos direitos fundamentais. (COELHO, 2005. p. 34).
}

\footnotetext{
${ }^{6}$ A própria colocação do catálogo dos direitos fundamentais no início do texto constitucional, bem como, a amplitude do rol do artigo $5^{\circ}$ denota a intenção do constituinte de emprestar significado especial e a posição de destaque concedida aos direitos fundamentais pela Constituição Federal. (MENDES, 2004. p. 1).

${ }^{7}$ A aplicabilidade restrita das normas de natureza programática decorreria da fluidez de suas disposições e da inexistência de instrumentos jurídico-processuais capazes de garantir sua concretização. Compreendendo que as relações econômico-sociais são disciplinadas apenas por normas programáticas, vide SILVA, 2008. p. 140-142.

${ }^{8}$ Liga-se a dimensão objetiva a compreensão de que os direitos fundamentais consagram os valores mais importantes da comunidade política potencializando a sua irradiação para todos os campos do Direito, e sua eficácia enquanto fins ou valores comunitários sobre uma miríade de relações jurídicas. SARMENTO, 2004. p. 371.

9 Com a introdução dos direitos fundamentais da segunda geração, passou-se a compreender os critérios objetivos de valores, bem como, os princípios básicos que animam a Constituição, projetando a sua unidade e
} 
Os direitos fundamentais também passam a corresponder, ao lado dos princípios estruturais e organizacionais, a um núcleo básico do ordenamento constitucional ${ }^{10}$ e a critério de interpretação das normas, categorias e institutos, em um fenômeno de abertura constitucional ou de constitucionalização em aberto, que importa na irradiação ou expansão da dignidade e dos direitos do homem ${ }^{11}$.

O Estado Democrático de Direito passa por uma abertura constitucional radicada no extenso catálogo de direitos fundamentais - civis, políticos, econômicos, sociais e culturais que, com epicentro no princípio da dignidade da pessoa humana, alcança a superação da tradicional divisão de domínio e papéis do Estado e da sociedade civil ${ }^{12}$ e torna-se garantidor de níveis mínimos desses direitos.

Transformam-se também os critérios de verificação da legitimidade do Estado. Essa passa a ser medida pelo grau de observância e de implementação dos direitos fundamentais, radicados da dignidade da pessoa humana, pelos poderes públicos de forma direta ou através da atuação de terceiros ${ }^{13}$.

Nota-se, portanto, que o caráter programático e dirigente da Constituição Federal de 1988, determina mais do que princípios e objetivos fundamentais, mas igualmente, programas e competências para os poderes públicos, reforçando a construção de um pluralismo constitucional que se adequa às complexidades das sociedades contemporâneas.

fazendo a congruência fundamental de suas regras. Esses direitos, passam a representar uma unidade de ordenação valorativa, de garantia contra arbítrios do Estado. BONAVIDES, 2003. p. 569.

${ }^{10}$ Os direitos fundamentais como resultado da personalização e positivação constitucional de determinados valores básicos para integrar a substância propriamente dita da Constituição formado pelas decisões fundamentais da ordem normativa, revelando que mesmo num Estado Democrático de Direito se torna necessária certas vinculações de cunho material para fazer frente aos espectros da ditadura e do totalitarismo. (SARLET, 2007. p. 61).

${ }^{11}$ É alçado em forja central da eclética e difusão produção de valores e princípios encarecidos pela sociedade contemporânea. (CASTRO, 2010, p. 20-21).

12 De certo modo, o postulado da dignidade humana universalizou-se como um polo de atração para cada vez mais novos direitos refletores de um novo modo de atuação do Estado Democrático de Direito. Assim, encontramos-o na Constituição do México de 1917 (Art. 3 II “c"), da Itália de 1947 (Art. 3), da Alemanha de 1949 (Art. $1^{\circ}$ ), de Portugal de 1976 com redação dada pela Lei Constitucional 1 de 1989 (Art. $1^{\circ}$ ). Espanha de 1978 (Art. 47) e na do Brasil de 1988 (art. $1^{\circ}$ III, art. 170, art. $226 \S 7^{\circ}$, art. 227 e 230). (CASTRO, 2010. p. 15 19).

${ }^{13}$ Uma Constituição que consagre um Estado de Direito não pode admitir que qualquer governante ou órgão do Estado possa agir arbitrariamente, fora dos limites constitucionais, sob pretexto de conveniência pública ou de necessidade e urgência que justifique a prática de atos arbitrários. O verdadeiro Estado de Direito é aquele que assegura a prática da democracia e a proteção da dignidade da pessoa humana. (DALLARI, 1995. p. 182-183). 
Assim, o direito constitucional à uma sociedade plural vai além da proteção ao pluralismo político ${ }^{14}$, pois também decorre do princípio fundamental do Estado Brasileiro o caráter compromissório com a justiça social da Constituição Cidadã, cujo objetivo é a redução de todas as desigualdades ${ }^{15}$.

Desta feita, fica claro que o constitucionalismo contemporâneo é essencialmente pluralista já que se baseia na proteção de direitos fundamentais em distintos ciclos e gerações consagrando a liberdade, igualdade e fraternidade, que pressupõe a proteção e garantia dos direitos fundamentais, em especial, daqueles que estão em posição desigual ${ }^{16}$.

\section{DIGNIDADE E MÍNIMO EXISTENCIAL}

Com epicentro na Constituição, o princípio ético-jurídico da dignidade passa a atribuir a unidade valorativa e sistemática ao ordenamento jurídico, regulamentando a autonomia de vontade em prol da solidariedade social, de forma a possibilitar que ocorra o livre desenvolvimento da personalidade de cada um dos membros da comunidade (MORAES, 2000, p. 55 e 59).

Não é nova a ideia que para o atendimento de uma vida com dignidade é necessário garantir o que Pontes de Miranda (1933. p. 28-30) chamava de um "mínimo vital”, a saber, o indispensável à existência, que não se confunde com a caridade ou esmola, mas um direito à subsistência exigível do Estado como forma de preservar e permitir a vida.

O conceito contemporâneo, porém, se conecta ao reconhecimento dado pelo Tribunal Administrativo Federal alemão de um Existenzminimum como um direito subjetivo construído a partir do princípio da dignidade da pessoa humana, da cláusula do Estado Social e dos direitos à liberdade e à vida. ${ }^{17}$

A construção da noção de mínimo existencial ligado ao conteúdo essencial dos direitos fundamentais parece atender a dimensão que eles assumem no que tange a dignidade,

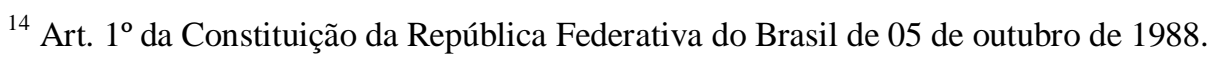

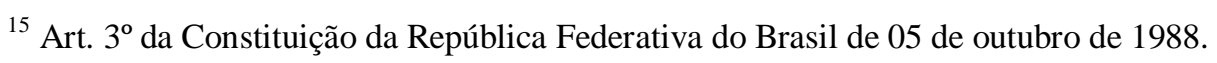

${ }^{16}$ Sobre o tema, vide: DIAS, 2003.

17 Tribunal Constitucional Federal da Alemanha. BVerfGE 40, 121 (1975). "A comunidade estatal deve assegurar-lhes pelo menos as condições mínimas para uma existência digna e envidar os esforços necessários para integrar estas pessoas na comunidade, fomentando o seu acompanhamento e apoio na família ou por terceiros, bem como criando as indispensáveis instituições assistenciais" SARLET In: SARMENTO, 2006. p. 565.
} 
porém, ainda parece limitar o mínimo existencial à um mínimo vital ligando mais a noção de sobrevivência do que de existência em toda sua potencialidade.

Outros apoiam que o mínimo existencial envolveria as condições fundamentais para uma vida com dignidade ${ }^{18} 19$, mas, também, os pressupostos essenciais para o funcionamento adequado do próprio sistema jurídico-democrático que constituem matriz irredutível, indisponível e insuscetível de restrição pelos poderes públicos e controlados pela jurisdição.

O conceito é de mínimo mas de existencial, a saber, não significa apenas a garantia da sobrevivência física, mas da vida, em toda potencialidade do ser, que deve abranger a garantia de acesso aos bens necessários, não apenas a manutenção da existência, mas da sua realização, o que alguns autores, apontarão como acesso a bens culturais, a inserção na vida social e a participação política (HARBELE, 2005, p. 116)

Sob tal entendimento o mínimo existencial realiza o complexo de direitos humanos fundamentais e garante o pluralismo constitucional ao assegurar ao indivíduo minimamente a sua inserção na vida social, política e cultural, ou seja, superar a desigualdade mediante o acesso aos bens necessários à realização do ser.

Uma vez que o sistema de proteção dos direitos humanos-fundamentais se articula na tutela e promoção dos direitos do homem, no âmbito internacional sob a égide dos tratados e convenções internacionais, bem como o ius cogens, e no âmbito nacional nos direitos constitucionais e legais, o mínimo existencial não pode ser a composição de alguns direitos.

Ao revés, deve compreender e se articular esse direito a tal sistema garantista, de forma a compor na sua dimensão do mínimo o acesso à realização do núcleo essencial dos direitos ligados ao homem em sua questão existencial, de modo a permitir a partir do seu conteúdo relacional e relativo, que sejam amplamente realizados.

Isso abrange admitir que o mínimo existencial não pode ser reduzido aos direitos individuais - como as liberdades, tal qual a vida - ou direitos sociais - como a saúde ou

\footnotetext{
${ }^{18}$ Neste sentido, Ana Paula de Barcellos (2002, p. 248), ao se referir ao mínimo existencial considera a distinção entre um núcleo essencial que deve ser reconhecida eficácia jurídica positiva e para além deste núcleo onde se desenvolvem outras modalidades de eficácia jurídica na preservação do espaço da política e das deliberações majoritárias.

19 É o que ocorre, por exemplo, com a educação fundamental e a medicina preventiva e de urgência que correspondendo respectivamente ao núcleo essencial do direito à educação e saúde, poderiam ser exigidas pelos indivíduos que precisem perante o Poder Judiciário sem restrições. Já o ensino superior e o médio e a medicina curativa exorbitariam este conteúdo, razão pelo qual, dependeriam da progressiva realização pelos poderes públicos. (TORRES, 2009. p. 54, 130, 255 e 267).
} 
educação - mas deve igualmente abranger minimamente a realização dos direitos políticos, coletivos e difusos necessários à realização da existência humana.

A projeção de um núcleo mínimo de direitos a serem garantidos ao cidadão tem sua origem fortemente demarcada no cenário internacional com os tratados de direitos fundamentais $^{20}$, os quais contribuem para a teoria geracional dos direitos humanos ${ }^{21}$. E com o passar histórico, estes passam a refletir nas gerações de direitos fundamentais, os quais foram internalizados pelos países em suas constituições. $\mathrm{O}$ meio ambiente ecologicamente equilibrado é um destes e foi reconhecido na qualidade de direito fundamental nas últimas décadas.

Documentos internacionais - pactos e tratados — dispõem de níveis mínimos de direitos que devem ser garantidos pelo país signatário, de modo a comprovar que este tem condições de cumprir o que fora acordado, caso contrário seria um claro descumprimento, pois sua razão de ser é justamente o alcance dos direitos ali estabelecidos e o avanço nessa direção ${ }^{22}$.

Nesse sentido, o conteúdo do mínimo existencial deve ser identificado como o núcleo essencial dos direitos fundamentais, a saber, como o reconhecimento de um mínimo de prestações necessárias à concretização mínima, essencial ou fundamental dos seus direitos necessários à uma existência livre e digna.

Assim que se pode ligar o mínimo existencial à noção de pluralismo constitucional, já que a garantia da promoção efetiva dos direitos fundamentais perpassa pelo

\footnotetext{
${ }^{20}$ Pacto Internacional dos Direitos Econômicos, Sociais e Culturais, ambos de 1966, além dos protocolos facultativos do Pacto dos Direitos Civis e Políticos que constituem a Carta Internacional dos Direitos do Homem $(\mathrm{CIDH})^{20}$ - International Bill of Rights, a qual inaugura o sistema global de proteção dos direitos humanos, do qual podem ser destacados os sistemas regionais europeu, interamericano e africano. (HOGEMANN, 2020, p. 240).

${ }^{21}$ É enfatizar o que Moyn afirma em Christian Human Rights. Ele escreve: "[A] tese geral dos Direitos Humanos Cristãos é que, através desta era de guerra perdida e esquecida, é igualmente senão mais viável considerar os direitos humanos como um projeto da direita cristã, não da esquerda secular. Sua criação provocou uma ruptura com a tradição revolucionária e seus droits de l'homme, ou - melhor dizendo - captura bem-sucedida dessa linguagem por forças que reformulam seu conservadorismo". Moyn considera que a dignidade humana se tornou um argumento central no discurso político cristão desde 1937. Para este autor, tanto os partidos democratas-cristãos quanto a própria Igreja Católica e as igrejas protestantes se encarregaram de promover a discussão sobre a piedade religiosa nos anos imediatamente seguintes. antes do início da Segunda Guerra Mundial. Por outro lado, com o fim da guerra, os governos da Europa Ocidental tentaram destacar esse processo. Assim, os direitos humanos acabam ganhando espaço público como resultado desses dois movimentos no início da Guerra Fria. (MOYN, 2015)
}

${ }^{22}$ Diplomatura en Derechos Economicos, Sociales, Culturales y Ambientales - DESCA 102. Faculdade de Direito. Universidade de Buenos Aires - UBA Internacional. 
reconhecimento da desigualdade e a busca dos instrumentos para superá-la mediante a efetivação de direitos, o que envolve o oferecimento de dadas prestações essenciais.

O mínimo existencial assume, por conseguinte, uma dimensão que ultrapassa a noção do Estado Liberal para a realização das liberdades públicas e do Estado Social, com a busca pela justiça social e concretização dos direitos sociais, qual seja, a do Estado Socioambiental, no qual se busca a efetivação dos direitos difusos, dentre os quais está o meio ambiente, e se torna o mínimo existencial ecológico.

\section{O ESTADO CONSTITUCIONAL ECOLÓGICO}

O Estado Constitucional Ecológico (ou Socioambiental de Direito), como abordado por Sarlet e Fensterseifer (2019), ganha pujança no ordenamento, não apenas por refletir os preceitos da norma constitucional, mas também por se adequar aos pressupostos históricos e à própria composição biótica brasileira.

Esse conceito se alinha aos novos paradigmas da ética ambiental, bem como ao reconhecimento do direito ao ambiente como direito fundamental da pessoa humana, "reconhecendo o caráter vital da qualidade ambiental para o desenvolvimento humano em níveis compatíveis com a dignidade que lhe é inerente" (FENSTERSEIFER, 2014, pp. 74 96).

Para Canotilho (2001, p. 9), o Estado Constitucional, além de ser e dever ser um Estado de Direito democrático e social, também deve ser um Estado regido por princípios ecológicos; o Estado ecológico uma expressão daquele, pautado em novas formas de participação política, denominada pelo autor de democracia sustentada.

O Estado Constitucional Ecológico é um conceito amplo que pressupõe uma concepção integrada ou integrativa do ambiente e, consequentemente, um direito integrado e integrativo do ambiente, em que haja a proteção deste em sua integralidade, por todos os aspectos (natural, físico, químico, biológico) e indivíduos (humano e não humano) que o compõem (CANOTILHO, 2001, p. 12).

Visão esta que, segundo o autor, impõe a passagem da compreensão monotemática para um entendimento multitemático que obriga a uma ponderação ou balanceamento dos direitos e interesses existentes de uma forma substancialmente inovadora. Avaliando os impactos ambientais no espectro público e no privado (CANOTILHO, 2001, p. 12). 
Desse modo, destaca-se a essência do artigo 225 da Constituição Federal, que representa o peso protetivo do direito ao meio ambiente ecologicamente equilibrado e a incumbência do Poder Público em preservar e restaurar os processos ecológicos essenciais e prover o manejo ecológico das espécies e ecossistemas, bem como proteger a fauna e a flora, vedadas, na forma da lei, as práticas que coloquem em risco sua função ecológica, provoquem a extinção de espécies ou submetam os animais a crueldade (art. $225, \S 1^{\circ}$, incisos I e VII).

Observa-se, portanto, que o escopo da norma constitucional é biocêntrico e visa garantir a proteção e a preservação da vida em todas as suas formas - sejam essas humanas ou não humanas - visando assegurar o direito ao meio ambiente ecologicamente equilibrado, o qual, para ser alcançado, deve possuir um patamar mínimo a ser garantido.

\section{BIOCENTRISMO E O MÍNIMO EXISTENCIAL ECOLÓGICO}

Conforme visto anteriormente, o conteúdo do mínimo existencial deve ser identificado como o núcleo essencial dos direitos fundamentais necessários à concretização mínima, essencial ou fundamental, de uma vida livre e digna.

Biocentrismo, como o próprio nome indica, é a teoria que reconhece a vida como o centro de importância, reconhecendo, portanto, o valor à esta intrínseco. Naconecy (2006, p. 64) definiu biocentrismo como Ética da Vida, onde "todo ser vivo, animado ou inanimado, tem valor moral em função das atividades biológicas que são normais à espécie a que ele pertence, nas condições normais para aquela espécie ${ }^{23, "}$

O biocentrismo vai além da sustentabilidade, a qual, por vezes, é justificativa para manutenção do status quo humano. Daniel Braga Lourenço (2019, p. 51-75) aponta que, sustentabilidade e antropocentrismo são faces de uma posição ambientalista tradicional.

Logo, a construção a partir desse paradigma ético-ambiental, demanda a consideração e proteção da vida ${ }^{24}$.

\footnotetext{
${ }^{23}$ Aqui incluindo-se crescimento, sobrevivência e reprodução.

${ }^{24}$ Destacam-se, ainda, as seguintes posições morais que, segundo Maldonado (2015, p. 126-127), seriam as mais relevantes para nortear a atuação sociopolítica humana frente ao Antropoceno e os desafios socioambientais atuais: " (i) frugality, advocating a frugal, non-capitalistic Anthropocene (the position endorsed by the majority of those critics of the concept that may be identified as members of the Counteranthropocene); (ii) restraint, demanding a new social contract on global sustainability that implements the idea of a benign human stewardship of nature; (iii) enlightenment, that links the re-arrangement of socionatural relations in the
} 
Pela perspectiva do "enfoque das capacidades", desenvolvido na economia por Amartya $\operatorname{Sen}^{25}$ e na filosofia por Martha Nussbaum, as capacidades são a base da "explicação das garantias humanas centrais que devem ser respeitadas e implementadas pelos governos de todas as nações, como um mínimo do que o respeito pela dignidade humana requer" (NUSSBAUM, 2013, p. 84), assim, garantem-se as capacidades dos indivíduos para garantir sua dignidade.

Isso demonstra que o mínimo existencial não deve ser confundido com dignidade. Aquele é pressuposto desse, mas possui conteúdo diverso. A dignidade é o fim que se busca ao atender e garantir esse conjunto mínimo de direitos sociais, econômicos, civis e ambientais, de modo a proporcionar ao indivíduo as capacidades que se requerem para um bem viver (NUSSBAUM, 2013, p. 84).

Assim, visando alcançar a compreensão do mínimo existencial ecológico, filia-se a ampliação do conceito de mínimo existencial - liberal, social e ecológico - empreendida por Fensterseifer (2014, p. 79) de modo a englobar a concepção de uma vida "com qualidade, equilíbrio e segurança ambiental (e, por óbvio, com dignidade)”. O que também se justifica em prol da sobrevivência humana — entendida pelo autor como mínimo vital —, face à ameaça em razão da degradação ambiental.

Conjuga-se à essa, as disposições normativas do ordenamento e da jurisprudência. $\mathrm{O}$ artigo $2^{\circ}$ da Política Nacional do Meio Ambiente (Lei $n^{\circ}$ 6.938/81), que estabelece enquanto objetivo "a preservação, melhoria e recuperação da qualidade ambiental propícia à vida, visando assegurar (...) à proteção da dignidade da vida humana”, e o art. 225 da Constituição Federal, que inaugura a percepção do meio ambiente ecologicamente equilibrado na qualidade de direito.

Nos tribunais, o voto da Ministra Eliana Calmon ${ }^{26}$, ao entender que a lesão ao patrimônio ambiental “(...) está protegida pelo manto da imprescritibilidade, por se tratar de direito inerente à vida, fundamental e essencial à afirmação dos povos, independentemente de

Anthropocene to an Anthropogenic Enlightenment that integrates the nonhuman world into the conversation about the good life and the good 127 society; and (iv) boldness, a position that accepts the disappearance of the benign conditions of the Holocene and vindicates a greater degree of socionatural engineering and experimentation as a way of neutralizing the dangers conjured up by the Anthropocene".

${ }^{25}$ Enquanto "mensuração comparativa da qualidade de vida" dos indivíduos contornada pela temática da justiça social (Sen, 2011).

${ }^{26}$ BRASIL. SUPERIOR TRIBUNAL DE JUSTIÇA. Recurso Especial (REsp) $\mathrm{n}^{\circ}$ 1.120.117/AC, $2^{\mathrm{a}}$ Turma, Ministra Relatora Eliana Calmon, julgado em 10 nov. 2009. 
não estar expresso em texto legal (...) antecedendo a todos os demais direitos, pois sem ele não há vida, nem saúde, nem trabalho, nem lazer (...)".

Concepções que endossam o entendimento do ambiente enquanto unidade básica, vital, imprescindível e essencial à concretização da dignidade, do bem estar e de outros diretos humanos (BIRNIE; BOYLE, 2002, p. 255 apud FENSTERSEIFER In: PERALTA; ALVARENGA; AUGUSTIN, 2014, p. 80)

Logo, o mínimo existencial ecológico é pressuposto do mínimo vital, devendo, portanto, ser garantido para abarcar todos os indivíduos compreendidos pelo Estado Socioambiental.

Nesse contexto, fica cada vez mais nítido que a garantia ao meio ambiente ecologicamente equilibrado para as presentes e futuras gerações é aplicável à sociedade interespécie (COCHRANE, 2018) e deve considerar, portanto, gerações de espécies humanas e não humanas ${ }^{27}$.

Milaré (2013, pp. 259 e 260) já sustenta há tempos que esse princípio tem cunho de solidariedade entre as gerações, visando garantir o usufruto do ambiente saudável. Ocorre que, para além do fenômeno da solidariedade intrageracional, estão a intergeracional e a interespécie (FENSTERSEIFER, 2020, p. 16).

Catarses ambientais, como as pandemias, que tem natureza zoonótica e decorrem da instrumentalização contínua dos animais $^{28}$ e da natureza ${ }^{29}$ (WALLACE, 2020), ratificam o

\footnotetext{
${ }^{27}$ Destaca-se que o texto constitucional não aponta que este direito seria restrito a pessoas humanas, razão pela qual entende-se plenamente cabível a extensão aos não humanos, principalmente, quando analisados e interpretados sistematicamente o caput do artigo $225 \mathrm{com}$ os respectivos incisos I e VII do parágrafo $\S 1^{\circ}$.

${ }^{28} \mathrm{O}$ confinamento excessivo e limitador de comportamentos naturais das espécies, assim como o manejo de processamento de nutrientes para alimentação e a união de espécies diversas conjuntamente em condições estressantes são traços característicos da produção industrial de animais, podem ser tidas como responsáveis pelo surgimento de doenças como a Síndrome Respiratória Aguda Grave (SARS), as influenzas aviária e suína e também a encefalite espongiforme bovina (Doença da Vaca Louca). (PERROTA, 2020, p. 3)

${ }^{29}$ A antropização ("perturbação") de habitats naturais da fauna silvestre, como a Floresta Amazônica, em que estes convivem com os patógenos de forma equilibrada, sendo seus hospedeiros em uma relação biologicamente equilibrada, tem potencial de agitar microrganismos diversos e de potencial letal desconhecido. "For a century, two new viruses per year have spilled from their natural hosts into humans. The MERS, SARS, and 2009 H1N1 epidemics, and the HIV and coronavirus disease 2019 (COVID-19) pandemics, testify to their damage. Zoonotic viruses infect people directly most often when they handle live primates, bats, and other wildlife (or their meat) or indirectly from farm animals such as chickens and pigs. The risks are higher than ever $(2,3)$ as increasingly intimate associations between humans and wildlife disease reservoirs accelerate the potential for viruses to spread globally". (DOBSON et al, 2020, p. 379)
} 
reconhecimento de um mínimo existencial ecológico para animais não humanos, de modo a efetivar a norma constitucional e, em última instância, proteger a própria vida humana.

Sabe-se que a discussão acerca do círculo de consideração moral dos animais não humanos ainda é objeto de grande debate ${ }^{30}$, assim como o embate persona $\mathrm{x}$ objeto ${ }^{31}$.

De todo modo, o atual ponto jurídico, político, socioambiental e sanitário atingido pela sociedade e pelas instituições, aliados à previsão normativa constitucional, comportam a superação das formas argumentativas e discursos de poder padronizados e que, inclusive, tem gerado retrocessos e danos ambientais praticamente irreparáveis ${ }^{32}$.

O conteúdo da norma constitucional é biocêntrico e sua expressão normativoecológica é protetiva das garantias inerentes ao alcance do mínimo vital. Logo, ela é capaz de proteger a vida e de garantir as capacidades básicas necessárias aos indivíduos não humanos, tais como saúde corporal, integridade física, controle sobre o próprio ambiente, dentre outros (NUSSBAUM, 2013, p. 426).

Observar o mínimo existencial ecológico pelo prisma da ética ecológica, na qual encontram-se as dimensões intrageracional, intergeracional e interespécie (FENSTERSEIFER, 2020, p. 16), ratifica a convergência entre os aspectos teóricos e normativos e, consequentemente, sua expansão em favor da proteção de humanos e não humanos.

E ainda que haja oposição à proteção das futuras gerações humanas e não humanas por suposta violação à expressão de liberdade do indivíduo, importa ressaltar dois pontos

\footnotetext{
${ }^{30}$ O filósofo Peter Singer (2011), já na década de 70, abordava acerca da necessidade de ampliação deste círculo para inclusão dos animais não humanos (fonte). Roderick Frazier Nash, historiador, tratou desta mesma expansão em sua obra The Rights of Nature (1989), no sentido de incluir a natureza, como objeto de consideração moral e, ainda, sujeito de direitos. (FENSTERSEIFER, 2020, p. 21). Acerca da perspectiva da natureza como sujeito de direitos, cabe apontar brevemente que tem como base teórica a "ecologia profunda" (Deep ecology), cujo conceito foi cunhado por Arne Naess (1990, p. 28); atualmente, é reconhecida pela Constituição do Equador (2008) e pela Lei da Mãe Terra, na Bolívia (2010), ambas pioneiras. Interessante também observar a construção sociopolítica que hoje já é feita sobre a perspectiva da natureza como sujeito de direitos, para Eduardo Gudynas seriam estabelecidos "diferentes tipos de cidadania (cidadania ambiental e metacidadania ecológica), ou dois tipos de justiça independentes: a justiça ambiental, que exige condições sociais equitativas e um meio ambiente sadio e não contaminado, e a justiça ecológica, relacionada à sobrevivência de espécies e ecossistemas como redes de vida." (GUDYNAS, 2009, pp. 34-47 apud SVAMPA In: DILGER; LANG; FILHO, 2016, p. 154).
}

\footnotetext{
${ }^{31}$ A título exemplificativo, recordam-se as emendas de $\mathrm{n}^{\circ} 1,2$ e 3 ao projeto de lei $\mathrm{n}^{\mathrm{o}} 27 / 2018$, que afastam a alteração do status jurídico do animal não-humano para sujeito de direito despersonificado e sua natureza jurídica para sui generis, para os animais utilizados na agropecuária, pesquisa científica e manifestações culturais.
}

${ }^{32}$ Nesse sentido, vale recordar as tragédias de Brumadinho e Mariana. 
nodais; primeiro: não há exercício de direitos sem restrições e aqui vê-se o direito fundamental à um ambiente saudável e ecologicamente equilibrado como tal. Segundo: para haver o exercício de tal liberdade há necessidade de manutenção de um espaço livre e democrático para tanto, o que não se vislumbra em um cenário de crise ecológica ${ }^{33}$.

No mais, importa recordar que, enquanto sociedade interespécie (COCHRANE, 2018) orientada por uma Constituição mutável a reverberar o verdadeiro significado constitucional de proteção e garantias, parece tratar-se de consequência lógica a recepção dos animais não humanos neste espaço normativo de proteção, de modo que todo o Estado Socioambiental de Direito possa ser efetivamente cumprido e respeitado.

\section{CONCLUSÃO}

O Brasil, hoje, atua mediante a representação do autoritarismo inerente ao seu processo histórico ${ }^{34}$, portanto, reforçar a existência do Estado Constitucional Ecológico é reforçar o escopo da norma constitucional e das bases protetivas nela constantes.

Nesse sentido, objetiva-se-trazer a lume a compreensão de que o corpo normativo constitucional é abarcado pelo paradigma biocêntrico, o qual aliado a compreensão do meio ambiente ecologicamente equilibrado, enquanto direito fundamental e antecedente a todos os demais direitos, permitiria a efetivação do mínimo existencial ecológico enquanto pressuposto do mínimo vital.

E, assim, seguindo o próprio texto constitucional e entendendo o ambiente como um espaço ocupado pela vida humana e não humana seria pertinente - e urgente - a ampliação do conteúdo do mínimo existencial ecológico para abarcar todos os indivíduos compreendidos pelo Estado Socioambiental de Direito.

Desse modo, resta nítido que o direito constitucional brasileiro reúne as condições para proteger o meio ambiente e todos que nele vivem e concretizar, de fato, o direito ao meio ambiente ecologicamente equilibrado para as presentes e futuras gerações de humanos e não humanos.

\section{REFERÊNCIAS:}

\footnotetext{
${ }^{33}$ Notícias publicadas pelo Estado de Minas Internacional e pelo Conjur, respectivamente: Equador prorroga estado de exceção devido a pandemia; Chile estende por mais 90 dias estado de exceção por pandemia; Cogitado por Bolsonaro, estado de sítio por coronavírus é inconstitucional, diz OAB.

34 “Somos um país muito original e jovem em matéria de vida institucional regular”. (SCHWARCZ, 2019, p. 5).
} 
ARIAS-MALDONADO, Manuel. Environment and Society Socionatural Relations in the Anthropocene. SpringerBriefs in political science. ISBN 978-3-319-15952-2 (eBook). Springer, 2015.

BARCELLOS, Ana Paula de. A eficácia jurídica dos princípios constitucionais: o princípio da dignidade da pessoa humana. Rio de Janeiro: Renovar, 2002.

BARROSO, Luís Roberto. Neoconstitucionalismo e constitucionalização do direito: O triunfo tardio do direito constitucional no Brasil. In: SOUZA NETO, Cláudio Pereira de; SARMENTO, Daniel (orgs.). A constitucionalização do direito: fundamentos teóricos $e$ aplicações específicas. Rio de Janeiro: Lumen Juris, 2007.

BONAVIDES, Paulo. Curso de direito constitucional. 13. ed. São Paulo: Malheiros, 2003.

BRASIL. Constituição da República Federativa do Brasil de 05 de outubro de 1988. Disponível em: <http://www.planalto.gov.br/ccivil_03/constituicao/constituicao.htm>

BRASIL. LEI No 6.938, DE 31 DE AGOSTO DE 1981. Dispõe sobre a Política Nacional do Meio Ambiente, seus fins e mecanismos de formulação e aplicação, e dá outras providências. Disponível em: <http://www.planalto.gov.br/ccivil_03/leis/L6938.htm> Acesso em 17 set. 2020.

BRASIL. SUPERIOR TRIBUNAL DE JUSTIÇA. Recurso Especial (REsp) no 1.120.117/AC, $2^{\text {a }}$ Turma, Ministra Relatora Eliana Calmon, julgado em 10 nov. 2009. Disponível em: $<$ https://ww2.stj.jus.br/processo/revista/documento/mediado/?componente=ATC\&sequencial $=8289468 \&$ num_registro $=200900740337 \&$ data $=20110428 \&$ tipo $=51 \&$ formato $=P D F>$ Acesso em 13 set. 2020.

CANOTILHO, José Joaquim Gomes. Estado constitucional ecológico e democracia sustentada. Impactum, Coimbra University Press. Revista do Centro de Estudos de Direito do Ordenamento, do Urbanismo e do Ambiente, Coimbra, v. 2, ano 4, p. 9-16, fevereiro, 2001, p. 9. Disponível em: <https://bit.ly/3o7DNyY> Acesso em 21 jan. 2021.

CASTRO, Carlos Roberto Siqueira. A Constituição Aberta e os Direitos Fundamentais: ensaios sobre o constitucionalismo pós-moderno e comunitário. Rio de Janeiro: Forense, 2010.

COCHRANE, Alasdair. Sentientist Politics: A Theory of Global Inter-Species Justice. Oxford: Oxford University Press, 2018.

COELHO, Rosa Júlia Plá. Mecanismos de Proteção dos Direitos Fundamentais. 1 ed. Brasília: Ordem dos Advogados do Brasil, 2005. 
DALLARI, Dalmo de Abreu. Elementos de teoria geral do estado. 19. ed. São Paulo: Saraiva, 1995.

DIAS, Maria Berenice. A igualdade desigual. Revista Brasileira de Direito Constitucional, v. 2, 2003.

Diplomatura en Derechos Economicos, Sociales, Culturales y Ambientales - DESCA 102. Faculdade de Direito. Universidade de Buenos Aires - UBA Internacional.

DOBSON, Andrew P.; PIMM, Stuart L.; HANNAH, Lee, KAUFMAN, Les; AHUMADA, Jorge A.; ANDO, Amy W.; BERNSTEIN, Aaron, Jonah Busch; DASZAK, Peter; ENGELMANN, Jens; KINNAIRD, Margaret F.; Binbin V. Li; LOCH-TEMZELIDES, Ted; LOVEJOY, Thomas; NOWAK, Katarzyna; ROEHRDANZ, Patrick R. And VALE, Mariana M.. Ecology and economics for pandemic prevention. Science, v. 369, issue 6502, pp. 379381. 24 jul. 2020, DOI: 10.1126/science.abc3189. Disponível em: <https://science.sciencemag.org/content/369/6502/379> Acesso em 02 abr. 2021

FENSTERSEIFER Tiago. Mínimo existencial ecológico (ou socioambiental): o direito fundamental às prestações materiais mínimas em termos de qualidade, equilíbrio e segurança ambiental para o desfrute de uma vida humana digna e saudável (pelas presentes e futuras gerações). In: PERALTA, Carlos E.; ALVARENGA, Luciano J.; AUGUSTIN, Sérgio (orgs.). Direito e justiça ambiental: diálogos interdisciplinares sobre a crise ecológica. Caxias do Sul: Educs, 2014. PP. 74 - 96.

FENSTERSEIFER, Tiago. Curso de Direito Ambiental. Aula 01: Introdução ao Pensamento Ecológico. PP. 1-27. Círculo de Estudos pela Internet, 2020.

HARBELE, Peter. A Dignidade humana como fundamento da comunidade estatal, in: I. W. Sarlet (org.), Dimensões da Dignidade. Ensaios de Filosofia do Direito e Direito Constitucional. Porto Alegre: Livraria do Advogado, 2005.

HESSE, Konrad. A força normativa da Constituição. Porto Alegre: Sergio Antonio Fabris Ed., 1991.

HOGEMANN, Edna Raquel. Human Rights beyond Dichotomy between Cultural Universalism and Relativism. The Age of Human Rights Journal. n. 14, p. 19-36, 2020. Disponível em: <https://revistaselectronicas.ujaen.es/index.php/TAHRJ/article/view/5476> Acesso em 10 jun. 2020.

LOURENÇO, Daniel Braga. Qual o valor da natureza? Uma introdução à ética ambiental. Rio de Janeiro: Editora Elefante, 2019. 
MENDES, Gilmar Ferreira. Direitos Fundamentais e Controle de Constitucionalidade: Estudos de Direito Constitucional. 3 ed., rev. e ampl., São Paulo: Saraiva, 2004.

MILARÉ, Edis. Direito do Ambiente. São Paulo. Revista dos Tribunais. $8^{\mathrm{a}}$ ed. 2013.

MORAES, Maria Celina Bodin de. Constituição e Direito Civil: Tendências in: Revista dos Tribunais. Vol. 779 set. 2000.

MOYN, Samuel. Christian Human Rights, University of Pennsylvania Press, 2015.

NACONECY, Carlos Michelon. Ética \& animais: um guia de argumentação. Porto Alegre: EDIPUCRS, 2006.

NAESS, Arne. Ecology, community and lifestyle. Cambridge University Press, 1990.

Notícia: Estado de Minas Internacional. Equador prorroga estado de exceção devido a pandemia. Disponível em:

<https://www.em.com.br/app/noticia/internacional/2020/06/16/interna_internacional,1157138 /equador-prorroga-estado-de-excecao-devido-a-pandemia.shtml> Publicado em 16 jun. 2020. Acesso em 16 set. 2020.

Notícia: Conjur. Chile estende por mais 90 dias estado de exceção por pandemia. Disponível em:

<https://www.em.com.br/app/noticia/internacional/2020/09/11/interna_internacional,1184730 /chile-estende-por-mais-90-dias-estado-de-excecao-por-pandemia.shtml> Publicado em 11 set. 2020. Acesso em 16 set. 2020.

Notícia: Conjur. Cogitado por Bolsonaro, estado de sítio por coronavírus é inconstitucional, diz $O A B$. Disponível em: <https://www.conjur.com.br/2020-mar-21/estado-sitio-coronavirusinconstitucional-oab> Publicado em 21 mar. 2020. Acesso em 16 set. 2020.

NUSSBAUM, Martha C. Fronteiras da justiça: deficiência, nacionalidade e pertencimento à espécie. São Paulo: Martins Fontes, 2013.

PERROTA, Ana Paula. Serpentes, morcegos, pangolins e 'mercados úmidos' chineses: Uma crítica da construção de vilões epidêmicos no combate à Covid-19. DILEMAS: Revista de Estudos de Conflito e Controle Social. Rio de Janeiro - Reflexões na Pandemia, 2020. pp. 16.

PONTES DE MIRANDA. Direitos à subsistência e direito ao trabalho. Rio de Janeiro: Alba Limitada, 1933.

SARLET, Ingo Wolfgang. A eficácia dos direitos fundamentais. 10. ed., rev., atual. e ampl., Porto Alegre: Livraria do Advogado, 2007. 
SARLET, Ingo Wolfgang. Direitos fundamentais sociais, mínimo existencial e direito privado: breves notas sobre alguns aspectos da possível eficácia dos direitos sociais nas relações entre particulares. In: SARMENTO, Daniel; GALDINO, Flávio (orgs.). Direitos fundamentais: estudos em homenagem ao Professor Ricardo Lobo Torres. Rio de Janeiro: Renovar, 2006.

SARMENTO, Daniel. Direitos Fundamentais e Relações Privadas. Rio de Janeiro: Lumen Juris, 2004.

SARMENTO, Daniel. O neoconstitucionalismo no Brasil: Riscos e possibilidades. In:

(org.). Filosofia e teoria constitucional contemporânea. Rio de Janeiro: Lumen Juris, 2009

SCHWARCZ, Lilia Katri Moritz. Sobre o autoritarismo brasileiro. São Paulo: Companhia das letras, 2019. (ebook).

SEN, Amartya. A ideia de justiça (2009). Tradução: Denise Bottmann, Ricardo Doninelli Mendes. São Paulo: Companhia Das Letras, 2011.

SILVA, José Afonso da. Aplicabilidade das normas constitucionais. 7. ed. São Paulo: Malheiros, 2008.

SINGER, Peter. The Expanding Circle. Ethics, Evolution, and Moral Progress. Princeton University Press, 2011.

SVAMPA, Maristella. Extrativismo neodesenvolvimentista e movimentos sociais. Um giro ecoterritorial rumo a novas alternativas? In: DILGER, Gerhard; LANG, Miriam; FILHO, Jorge Pereira (orgs.). Descolonizar o imaginário: debates sobre pós-extrativismo e alternativas ao desenvolvimento. Tradução: Igor Ojeda. - São Paulo: Fundação Rosa Luxemburgo; Autonomia Literária; Editora Elefante, 2016. P. 141-171.

TORRES, Ricardo Lobo. O direito ao mínimo existencial. Rio de Janeiro: Renovar, 2009.

WALlACE, Rob. Pandemia e agronegócio: doenças infecciosas, capitalismo e ciência. Tradução: Allan Rodrigo de Campos Silva. Editora Elefante \& Igra Kniga, 2020. 